\title{
FORMAÇÃO DE MUDAS DE CAFEEIRO EM SUBSTRATOS ORIUNDOS DE DIFERENTES MÉTODOS DE DESINFESTAÇÃO ( $\left.{ }^{1}\right)$
}

\author{
GUSTAVO RABELO BOTREL MIRANDA ${ }^{(2)}$; RUBENS JOSÉ GUIMARÃES ${ }^{(3)}$; ÉLBERIS PEREIRA \\ BOTREL ${ }^{(4)}$; VICENTE PAULO CAMPOS ${ }^{(5)}$; GUSTAVO RENNÓ REIS ALMEIDA ${ }^{(6)}$; \\ RAPHAEL GARCIA GONZALEZ ${ }^{(7)}$
}

\begin{abstract}
RESUMO
Objetivando verificar o desenvolvimento de cafeeiro oriundos de diferentes métodos de tratamento de substratos utilizados na produção de mudas em saquinhos de polietileno, instalou-se em maio/2004 em um viveiro na Universidade Federal de Lavras o presente experimento. Foram utilizados treze tratamentos para a desinfestação de substratos, sendo utilizado o padrão para mudas de café com solo coletado de uma lavoura cafeeira de 20 anos. Utilizou-se a cultivar paraíso H 419-1. Avaliou-se o crescimento das plantas de cafeeiro quando estavam com 5 pares de folhas verdadeiras, sendo: altura de plantas $(\mathrm{cm})$, diâmetro de caule $(\mathrm{mm})$, massa seca do sistema radicular $(\mathrm{g})$, massa seca da parte aérea $(\mathrm{g})$, número de nós da inserção foliar do ramo ortotrópico da muda e área foliar total $\left(\mathrm{cm}^{2}\right)$. Concluiu-se que o uso do coletor solar é promissor para a desinfestação de substratos por proporcionar bom desenvolvimento de mudas de cafeeiro, a exemplo do brometo de metila.
\end{abstract}

Palavras-chave: café, desinfestação, substratos, brometo de metila, mudas.

\section{ABSTRACT \\ COFFEE SEEDLINGS PRODUCTION POTTING MIXTURES FROM DISINFESTATIONS METHODS}

The objective of this work was to evaluate the development of coffee seedlings grown in bag mixture disinfested by different methods. The work was carried out in a high cover coffee nursery at Federal University of Lavras, State of Minas Gerais, Brazil, in May/2004. The bag mixture was prepared using soil from a 20 years old coffee field. Thirteen disinfestations methods were used in bag mixture. The cultivar paraíso H 419-1 was used in all treatments. The growth was evaluated when the plants had five pairs of mature leaves. The following parameters were analyzed: height $(\mathrm{cm})$, girth diameter $(\mathrm{mm})$, root and shoot dry weight $(\mathrm{g})$, number of orthotropic nodes, and total leaf area $\left(\mathrm{cm}^{2}\right)$. It was concluded

( $\left.{ }^{1}\right)$ Parte do trabalho de mestrado do primeiro autor. Recebido para publicação em 21 de setembro de 2005 e aceito em 4 de maio de 2006.

( $\left.{ }^{2}\right)$ Setor de Cafeicultura do Departamento de Agricultura (DAG), Universidade Federal de Lavras (UFLA), Caixa Postal 3037, 37200-000 Lavras (MG). E-mail: grbmiranda@gmail.com. Bolsista CNPq.

$\left(^{3}\right)$ Departamento de Fitotecnia, Universidade Federal de Lavras (UFLA), Lavras (MG). E-mail: rubensjg@ufla.br.

$\left({ }^{4}\right)$ Fazenda Experimental da EPAMIG, Campus Universitário da Universidade Federal de Lavras, Caixa Postal 3037, 37200-000 Lavras (MG).E-mail: elberis@ufla.br.

$\left(^{5}\right)$ Departamento de Fitopatologia, Universidade Federal de Lavras (UFLA), Lavras (MG). E-mail: vpcampos@ufla.br.

$\left({ }^{6}\right)$ Fundação Procafé, Alameda do Café, 1000, Bairro Jardim Andere, 37026-400 Varginha (MG). E-mail: gustavo@fundacaoprocafe.com.br

( ${ }^{7}$ ) Graduando em Agronomia pela Universidade Federal de Lavras. E-mail: raphaelpokemon@gmail.com 
that methyl bromide promoted the best coffee seedlings development. The use of the solar collector was also considered promising for substrate disinfestations in commercial nurseries, as observed for the methyl bromide.

Key words: Coffee, disinfestation, potting mixtures, methyl bromide, seedlings.

\section{Introdução}

O Brasil é o maior produtor mundial de café há mais de 150 anos (GUIMARÃES et al., 2002) e, no período de 1994/95 a 2000/01 representou 25,7\% da produção mundial (FLORIANI, 2001). O Sul de Minas tem contribuído com $50 \%$ da produção estadual (UniversidAde IlLy do CAFÉ, 2005).

Por se tratar de cultura perene, falhas na formação da lavoura poderão ocasionar conseqüências maléficas por toda a vida da cultura (CARVALHO, 1978; GonÇALVES E TOMAZIELLO, 1970). Assim, a produção de mudas é uma das principais fases da cultura do cafeeiro, havendo a opção de se produzir em tubetes de polietileno rígido ou em saquinhos de polietileno; nesse último, utiliza-se solo como substrato. Todavia, a presença de nematóides, fungos de solo e sementes de plantas invasoras obrigam o viveirista a utilizar produtos esterilizantes de solo, muitas vezes com prejuízos ao meio ambiente, como é o caso do Brometo de Metila, que tem efeito altamente destruidor da camada de ozônio.

A Reunião das Partes do Protocolo de Montreal, realizada em Viena em dezembro de 1995, estabeleceu prazos para a eliminação do Brometo de Metila do mercado. Outros produtos estão disponíveis, mas nenhum possui as características do Brometo no tratamento de solo. Além disso, a pressão da sociedade por uma agricultura com menores impactos ambientais tem incentivado trabalhos de pesquisa com métodos não-químicos em substituição ao Brometo (CAmpanhola e Bettiol, 2003).

Diante da ausência de resultados comparativos dos métodos de desinfestação de substratos, nesse trabalho procurou-se verificar o desenvolvimento do café para produção de mudas em saquinhos de polietileno, desenvolvidas em substratos tratados com diferentes métodos de desinfestação.

\section{Material e Métodos}

O experimento foi instalado em maio/2004 na área experimental do Departamento de Fitopatologia (DFP) da UFLA, Sul do Estado de Minas Gerais, e desenvolvido até março/2005. A rega das mudas foi realizada diariamente, variando de uma a duas, conforme a retenção de água observada no substrato.
Durante período do experimento a temperatura média do mês mais quente foi de $22,5^{\circ} \mathrm{C}$ e a do mês mais frio, de $15,7^{\circ} \mathrm{C}$; a precipitação pluvial média mensal durante o período foi de $128,83 \mathrm{~mm}$ e a umidade relativa média mensal, de $73,2 \%$, de acordo com os dados registrados pela estação meteorológica da UFLA.

O delineamento experimental foi o de blocos casualizados com 13 tratamentos constituídos de métodos de desinfestação de substrato, com 4 blocos. Cada parcela foi composta de 36 mudas, sendo 4 na área útil e 32 na bordadura dupla.

O solo foi coletado no município de Carmo da Cachoeira (MG), em uma lavoura de café com nematóide (Meloidogyne exigua G.) com mais de 20 anos de produção, em três datas distintas, quinzenalmente, para que fossem aplicados os tratamentos de solarização e completassem os tempos de exposição ao sol exatamente no mesmo dia. O solo para os demais tratamentos foi coletado juntamente com o último tratamento de solarização, ou seja, faltando 15 dias para o enchimento dos saquinhos e a instalação de todo o experimento.

O substrato utilizado foi o padrão, de acordo com Comissão de Fertilidade Do Solo do Estado de Minas Gerais - CFSEMg (1999) e Guimarães et al. (2002), composto de 700 litros de solo e 300 litros de esterco de curral por metro cúbico de mistura, sendo adicionados $1,0 \mathrm{~kg}$ de $\mathrm{P}_{2} \mathrm{O}_{5}$ (5 $\mathrm{kg}$ de superfosfato simples) e $0,3 \mathrm{~kg}$ de $\mathrm{K}_{2} \mathrm{O}$ (0,5 $\mathrm{kg}$ de cloreto de potássio).

Os tratamentos de desinfestação utilizados foram de origem física e química, conforme citados e descritos a seguir: a) Testemunha: sem tratamento para desinfestação; b) Brometo de Metila: substrato tratado por 4 dias com uma lata de Brometo de Metila $(390 \mathrm{~mL})$, e revolvido 3 vezes por dia durante 5 dias após o tratamento; c) Autoclave: substrato foi autoclavado duas vezes durante uma hora, a $121{ }^{\circ} \mathrm{C}$ por vez; d) e) e f) Solarização com 15, 30 e 45 dias: foram utilizadas três lonas plásticas transparentes que cobriram todos os três substratos separadamente por cima e por baixo, formando assim, uma espécie de envelope com o substrato, com dimensões de $80 \mathrm{~cm}$ x $80 \mathrm{~cm} \times 20 \mathrm{~cm}$ em cada tratamento. Os substratos desses tratamentos ficaram expostos ao sol por 15, 30 e 45 dias, respectivamente; g) Coletor solar: foi construído um equipamento denominado Coletor solar desenvolvido por GHINI (1997). O tratamento foi de 3,5 
dias de exposição (Miranda, 2005); h) Fogo direto: utilizou-se um lança-chamas para aplicação do tratamento logo após o preparo do substrato. Foi feito um canteiro com o substrato, (mesmas dimensões do item d) para aplicar o fogo por um minuto de maneira uniforme, sem revolvimento do substrato, com uma intensidade de chama alta a uma distância de aproximadamente $20 \mathrm{~cm}$ entre o bico do lança-chamas e o substrato. i) Fosfeto de alumínio: foram colocadas três pastilhas (27 gramas) do produto junto ao substrato (mesmas dimensões do item d), debaixo da lona vedada, a fim de que não escapasse o gás. Após 3 dias de tratamento do substrato, retirou-se a lona e o substrato foi revolvido durante 3 dias para que não houvesse resíduo do produto; j) Quintozene 750 PM (PCNB): utilizando a dose de $10 \mathrm{~g}$ do produto comercial Quintozene para 2 litros de água, regou-se esse volume de calda nos 144 saquinhos com substrato; k) e 1) Formol (3 litros); Formol (2 litros): foram regados nos substratos (mesmas dimensões do item d), soluções de 3 e 2 litros de formalina (Royal Pharmaceutical Society of Great BRITANI - RPSGB, 1996) respectivamente, na concentração de 1 litro de formol para 20 litros d'água. Após a rega da solução com Formol, os substratos foram vedados com lona de polietileno preto (durante 3 dias) a fim de evitar a volatilização da formalina. Após esse período, retiraram-se as lonas e revolveramse os substratos tratados 2 vezes por dia, durante 3 dias; m) Hipoclorito de Sódio: tratamento de substrato na concentração de 5 litros de solução de Hipoclorito de Sódio a $12 \%$ de cloro ativo para 100 litros de substrato, os quais foram regados sobre o substrato uniformemente. Após a rega da solução com Hipoclorito, o substrato foi vedado com lona de polietileno preto durante 4 dias. Após esse período, retirou-se a lona e revolveu-se o substrato tratado 2 vezes por dia, durante 4 dias.

Para avaliação do desenvolvimento das mudas de cafeeiro repicou-se plântulas, em estágio de orelhade-onça, cultivar Paraíso H 419-1, em saquinhos de polietileno preto perfurados, $\mathrm{com} 11 \mathrm{~cm}$ de largura por $20 \mathrm{~cm}$ de comprimento.

Para avaliação de altura $(\mathrm{cm})$, diâmetro de caule $(\mathrm{mm})$, área foliar $\left(\mathrm{cm}^{2}\right)$, massa seca da parte aérea $(\mathrm{g})$, do sistema radicular $(\mathrm{g})$, contagem de galhas e número de nós de inserção foliar do ramo ortotrópico das mudas, no fim do experimento procedeu-se à lavagem das mudas, cortando-as na altura do colo. Para a avaliação da área foliar total foi utilizada a fórmula confirmada por Gomide et al. (1976); ou seja, a multiplicação do comprimento da folha com a maior largura desta, multiplicada pela constante 0,667 , e o resultado é multiplicado por 2 , ao final soma-se a área de todos os pares, a fim de obter a área foliar/planta.
Foi realizada análise estatística dos dados dos tratamentos referentes ao desenvolvimento do cafeeiro, pelo teste $\mathrm{F}$, aos níveis de $1 \%$ e $10 \%$. Quando diferenças significativas foram detectadas, as médias foram comparadas pelo teste de Scott-Knott. Foi utilizado o programa estatístico SISVAR 4.3, desenvolvido por FERREIRA (2000).

\section{Resultados e Discussão}

Não foi encontrada diferença significativa entre os tratamentos propostos quando se avaliaram "número de nós da inserção foliar do ramo ortotrópico e massa seca do sistema radicular" Não foram verificadas galhas de nematóides nas raízes do cafeeiro.

a) Altura de plantas ( $\mathrm{cm})$ : Observa-se que nos tratamentos de substratos realizados com Brometo de Metila, coletor solar, solarização com 30 dias, autoclave, testemunha, hipoclorito de sódio, solarização com 45 dias e fogo direto, as alturas foram maiores que as demais, não diferindo entre si (Tabela 1).

Observa-se que além do prejuízo em altura das mudas produzidas em substrato tratado com o fosfeto de alumínio, este produto é altamente tóxico e proporciona riscos ao meio ambiente (ANDREI, 1996; BERNARDO QUímicA, 19 -).

Os resultados obtidos com o tratamento de mudas com PCNB divergem dos obtidos por MENDONÇA et al. (2000), que não observaram queda no desenvolvimento de mudas de cafeeiro quando este produto foi aplicado por meio de regas.

Observa-se que o tratamento de substratos por hipoclorito de sódio não prejudicou o crescimento das mudas de cafeeiro. Estudos realizados por FAGUNDES et al. (2004) mostram que o uso do hipoclorito de sódio na parte aérea para controle de cercosporiose e ferrugem não tem efeito residual na planta até a dose testada. De acordo com CARActerística... (2005), o hipoclorito de sódio libera cloro gasoso quando entra em contato com algum tipo de ácido ou solução ácida.

Um fato ocorrido na avaliação da característica "altura" foi à melhora de desenvolvimento das plantas a partir do aumento de exposição do substrato ao tratamento de solarização. Observa-se que o tratamento de solarização com 15 dias foi o único dentre os métodos físicos que retardou o desenvolvimento de altura das plantas de café. 
Tabela 1. Valores médios das variáveis respostas: altura de plantas, diâmetro de caule, massa seca da parte aérea e área foliar no desenvolvimento de plantas de café, em diferentes métodos de desinfestação de substratos para produção de mudas. UFLA, Lavras, MG, 2005

\begin{tabular}{lrrrr}
\hline \multirow{2}{*}{ Tratamento } & \multicolumn{3}{c}{ Variável } \\
\cline { 2 - 5 } & Altura** & Diâmetro** $^{* *}$ & MSPA $^{*}$ & Área Foliar* $^{*}$ \\
\cline { 2 - 5 } Testemunha & $13,40 \mathrm{a}$ & $2,99 \mathrm{a}$ & $2,01 \mathrm{~b}$ & $180,88 \mathrm{~b}$ \\
Brometo de Metila & $14,79 \mathrm{a}$ & $3,19 \mathrm{a}$ & $2,30 \mathrm{a}$ & $214,10 \mathrm{a}$ \\
Autoclave & $13,73 \mathrm{a}$ & $3,01 \mathrm{a}$ & $2,29 \mathrm{a}$ & $191,31 \mathrm{~b}$ \\
Fosfeto de Alumínio & $12,50 \mathrm{~b}$ & $2,92 \mathrm{~b}$ & $1,93 \mathrm{~b}$ & $187,30 \mathrm{~b}$ \\
PCNB & $11,63 \mathrm{~b}$ & $2,84 \mathrm{~b}$ & $1,86 \mathrm{~b}$ & $160,13 \mathrm{~b}$ \\
Coletor solar & $13,93 \mathrm{a}$ & $3,01 \mathrm{a}$ & $2,22 \mathrm{a}$ & $221,27 \mathrm{a}$ \\
Solarização (15dias) & $12,18 \mathrm{~b}$ & $2,91 \mathrm{~b}$ & $2,03 \mathrm{~b}$ & $172,49 \mathrm{~b}$ \\
Solarização (30dias) & $13,90 \mathrm{a}$ & $3,11 \mathrm{a}$ & $2,10 \mathrm{~b}$ & $185,01 \mathrm{~b}$ \\
Solarização (45dias) & $13,28 \mathrm{a}$ & $3,11 \mathrm{a}$ & $2,00 \mathrm{~b}$ & $174,45 \mathrm{~b}$ \\
Formol (3 litros) & $12,23 \mathrm{~b}$ & $2,80 \mathrm{~b}$ & $2,03 \mathrm{~b}$ & $180,26 \mathrm{~b}$ \\
Formol (2 litros) & $12,64 \mathrm{~b}$ & $2,73 \mathrm{~b}$ & $1,99 \mathrm{~b}$ & $170,18 \mathrm{~b}$ \\
Hipoclorito de Sódio & $13,31 \mathrm{a}$ & $3,08 \mathrm{a}$ & $1,96 \mathrm{~b}$ & $171,40 \mathrm{~b}$ \\
Fogo direto & $13,05 \mathrm{a}$ & $2,79 \mathrm{~b}$ & $1,92 \mathrm{~b}$ & $181,69 \mathrm{~b}$ \\
\hline C.V. (\%) & - & 7,35 & 5,36 & 9,83 \\
\hline
\end{tabular}

Médias seguidas pela mesma letra na coluna não diferem entre si pelo teste de Scott-knott ao nível de 1\% para altura e diâmetro; e 10\% de probabilidade para massa seca da parte aérea e área foliar.

**, *: significativo ao nível de $1 \%$ e $10 \%$, pelo teste $\mathrm{F}$ respectivamente. Os valores de MBPA apresentados foram transformados em raiz quadrada de $X$.

b) Diâmetro de caule ( $\mathrm{mm})$ : Os tratamentos que atingiram melhor desenvolvimento para esta variável foram as plantas formadas nos substratos tratados com Brometo de Metila, solarização com 45 dias, solarização com 30 dias, hipoclorito de sódio, autoclave, coletor solar e testemunha (Tabela 1).

O resultado de diâmetro de caule foi semelhante aos resultados para altura, com exceção do tratamento com fogo direto, que prejudicou o desenvolvimento da espessura do diâmetro de caule de café.

A discussão dos demais tratamentos para o caractere diâmetro de caule pode ser considerada igual ao caractere altura de plantas, visto que os resultados foram idênticos.

c) Massa seca da parte aérea (g): Para essa variável foi observado melhor desenvolvimento nas plantas formadas nos substratos tratados com Brometo de Metila, autoclave e coletor solar (Tabela 1).

Mais uma vez, o tratamento com o uso do coletor solar se igualou aos tratamentos com Brometo de Metila e autoclave, endossando as afirmações de Campanhola e Bettiol (2003) de que o coletor solar substitui integralmente o uso do Brometo de Metila, além de, na solarização, ocorrer uma combinação de métodos químicos, físicos e biológicos que acarretam queda drástica na viabilidade de fungos fitopatogênicos (PAtricio, 2000 e GHini, 1997), o que pode inclusive favorecer o desenvolvimento de mudas de cafeeiro.

d) Área foliar total $\left(\mathrm{cm}^{2}\right)$ : Os tratamentos que sobressaíram nesta variável, foram, novamente, os substratos tratados com o coletor solar e o brometo de metila (Tabela 1).

A discussão para essa variável pode ser explicada da mesma forma que na variável massa seca da parte aérea, pois os resultados foram os mesmos, à exceção do tratamento com autoclave, inferior aos tratamentos com coletor solar e Brometo.

\section{Conclusões}

1. Brometo de Metila e o coletor solar foram os tratamentos mais eficazes quanto ao desenvolvimento proporcionado às mudas de cafeeiro nele produzidas. 
2. O formol, PCNB e o fosfeto de alumínio prejudicaram o desenvolvimento das mudas de café, nos substratos em que foram utilizados.

\section{Referências}

ANDREI, E. Compêndio de defensivos agrícolas: guia prático de produtos fitossanitários para uso agrícola. 5.ed. São Paulo: Organização Andrei, 1996. 506.

BERNARDO QUÍMICA COMÉRCIO E INDÚSTRIA. Gastoxin: Fosfeto de Alumínio. São Vicente, SP, [19-]. Bula.

CAMPANHOLA, C.; BETTIOL, W. Métodos alternativos de controle fitossanitário. Jaguariúna: Embrapa Meio Ambiente, 2003. 279p.

CARACTERÍSTICAS do Hipoclorito de Sódio. Carbocloro. Disponível em: <http:/ /www.carbocloro.com.br/produtos/ arquivos/fispq_hipoclorito_de_sodio.pdf $>$. Acesso em: $1 .^{\circ}$ jun. 2005.

CARVALHO, M.M. Formação de mudas. Informe Agropecuário, Belo Horizonte, v.4, n.44, p.14-8, ago. 1978.

COMISSAO DE FERTILIDADE DO SOLO DO ESTADO DE MINAS GERAIS. Recomendações para o uso de corretivos e fertilizantes em Minas Gerais: $5^{\mathrm{a}}$ aproximação. Viçosa, MG, 1999. $359 \mathrm{p}$.

FAGUNDES, A.V. et al. Uso de Hipoclorito de Sódio no controle de Cercosporiose do cafeeiro (Cercospora coffeicola berk \& cooke). In: ENCONTRO SUL MINEIRO DE CAFEICULTURA, 2004, Lavras, MG. Anais... Lavras, MG: EMATER/UFLA/Governo de MINAS GERAIS, 2004. v.10. (CD-ROOM)

FERREIRA, D.R. Análises estatísticas por meio do Sisvar para Windows versão 4.0. In: REUNIÃO ANUAL DA REGIÃO BRASILEIRA DA SOCIEDADE INTERNACIONAL DE BIOMETRIA, 45., 2000, São Carlos. Anais... São Carlos: UFSCar, 2000. p.255-258.
FLORIANI, C.G. Cafés de Minas: pioneirismo em certificação e marketing. Belo Horizonte: IMA, 2001. 36p. (Agro Tec. Caderno Técnico, 4)

GHINI, R. Desinfestação do solo com o uso de energia solar: solarização e coletor solar. Jaguariúna, SP: Embrapa - CNPMA, 1997. 29p. (Circular, 1)

GOMIDE, M.B. et al.. Comparação entre métodos de determinação de área foliar em cafeeiros Mundo Novo e Catuaí. 1976. Disponível em: <http:/ / www.sbicafe.ufv.br/ PDF/Conteudo/51822_Art088f.PDF> Acesso em: 2 jun. 2005.

GONÇALVES, J.C.; TOMAZIELO, R.A. Produção de mudas de café. Campinas: CATI, 1970. 25p. (Boletim Técnico, 63)

GUIMARÃES, R.J.; MENDES, A.N.G.; SOUZA, C.A.S. Cafeicultura. Lavras: UFLA/FAEPE, 2002. 317p.

MENDONÇA, J.M.A. et al. Eficiência do Monceren 25\% PM (Pencycuron) no controle do tombamento causado por Rhizoctonia solani em plântulas de cafeeiro (Coffea arabica L.) In: SIMPÓSIO DE PESQUISA DOS CAFÉS DO BRASIL, 2000, Poços de Caldas, MG. Anais... Poços de Caldas, MG: MAPA/ EMBRAPA, 2000. v.1, p.253-256.

MIRANDA, G.R.B. Métodos alternativos de desinfestação de substratos para formação de mudas de cafeeiro (Coffea arabica L.). 2005. 64p. Dissertação (Mestrado em Fitotecnia)Universidade Federal de Lavras, Lavras.

PATRICIO, F.R.A. Solarização do solo em ambiente protegido e sua integração com controle biológico ou químico na viabilidade de Pythium aphanidermatum e Rhizoctonia solani. 2000. 89p. Tese (Doutorado em Fitopatologia)-Escola Superior de Agricultura "Luiz de Queiroz", Piracicaba.

ROYAL PHARMACEUTICAL SOCIETY OF GREAT BRITANI. Martindale: the extra pharmacopoeia. 31.ed. London, 1996. p.1131-1132.

UNIVERSIDADE ILLY DO CAFÉ. Representação da produção de café da Região Sul de Minas no Estado. Disponível em: < h t t p : / / w w w. unill y. co m. b r / s i t e / noticias.exibir.do?idNoticia=157>. Acesso em: 6 jun. 2005. 